\title{
DIAGNOSTIC ACCURACY OF 68Ga-PSMA PET/MRI AND MULTIPARAMETRIC MRI IN DETECTING INDEX TUMOR IN RADICAL PROSTATECTOMY SPECIMEN
}

\author{
UGUR COSAR $^{1}$, Ilker Sen ${ }^{1}$, Uguray Aydos ${ }^{1}$, Murat Yavuz Koparal ${ }^{2}$, Murat Ucar ${ }^{1}$, Nil \\ Tokgoz $^{1}$, Ipek Isık Gonul ${ }^{1}$, Umit Ozgur Akdemir ${ }^{1}$, Lutfiye Ozlem Atay ${ }^{1}$, and Sinan Sözen ${ }^{1}$ \\ ${ }^{1}$ Gazi University Faculty of Medicine \\ ${ }^{2}$ Recep Tayyip Erdogan University Training and Research Hospital
}

February 21, 2021

\begin{abstract}
ABSTRACT Objective To evaluate the diagnostic accuracy of the $68 \mathrm{Gallium}$ (68Ga) - prostate specific membrane antigen (PSMA) positron emission tomography/magnetic resonance imaging (PET/MRI) and multiparametric MRI (mpMRI) by regionbased comparison of index tumour localisations using histopathological tumour maps of patients who underwent radical prostatectomy due to clinically significant prostate cancer. Patients and Methods The study included 64 patients who underwent radical prostatectomy after primary staging with mpMRI and 68Ga-PSMA PET/MRI. Diagnostic analysis was performed by dividing the prostate into four anatomic regions as left/right anterior and left/right posterior. The extension of the lesions in mpMRI and the pathological uptake in 68Ga-PSMA PET/MRI were matched separately for each region with the extension of the index tumour into each region. Results The sensitivity, specificity, positive predictive value, negative predictive value, positive likelihood ratio, negative likelihood ratio, and the accuracy of mpMRI and 68Ga-PSMA PET/MRI are shown as $55.7 \%$, $91.8 \%, 80.6 \%, 77.2 \%, 78.1 \%$ and $60.8 \%, 94.3 \%, 86.8 \% 79.8 \%, 83.5 \%$, respectively. 68Ga-PSMA PET/MRI has higher sensitivity and specificity compared with mpMRI. However, no statistically significant difference was found $(\mathrm{p}=0.464)$. Combined imaging had significantly higher diagnostic accuracy compared with mpMRI and 68Ga-PSMA PET/MRI (change in AUC: 0.084 and $0.046, \mathrm{p}<0.001$ and $\mathrm{p}=0.028$, respectively), while no statistically significant difference was found between mpMRI and 68Ga-PSMA PET/MRI (change in AUC: 0.038, $\mathrm{p}=0.246$ ). Conclusion 68Ga-PSMA PET/MRI had higher clinical diagnostic accuracy in prostate cancer compared with mpMRI. Diagnostic accuracy was significantly increased in the combined use of both imaging modalities.
\end{abstract}

DIAGNOSTIC ACCURACY OF ${ }^{68}$ Ga-PSMA PET/MRI AND MULTIPARAMETRIC MRI IN DETECTING INDEX TUMOR IN RADICAL PROSTATECTOMY SPECIMEN

\section{ABSTRACT}

\section{Objective}

To evaluate the diagnostic accuracy of the ${ }^{68}$ Gallium $\left({ }^{68} \mathrm{Ga}\right)$ - prostate specific membrane antigen (PSMA) positron emission tomography/magnetic resonance imaging (PET/MRI) and multiparametric MRI (mpMRI) by region-based comparison of index tumour localisations using histopathological tumour maps of patients who underwent radical prostatectomy due to clinically significant prostate cancer.

\section{Patients and Methods}

The study included 64 patients who underwent radical prostatectomy after primary staging with mpMRI and ${ }^{68}$ Ga-PSMA PET/MRI. Diagnostic analysis was performed by dividing the prostate into four anatomic 
regions as left/right anterior and left/right posterior. The extension of the lesions in mpMRI and the pathological uptake in ${ }^{68}$ Ga-PSMA PET/MRI were matched separately for each region with the extension of the index tumour into each region.

\section{Results}

The sensitivity, specificity, positive predictive value, negative predictive value, positive likelihood ratio, negative likelihood ratio, and the accuracy of mpMRI and ${ }^{68} \mathrm{Ga}$-PSMA PET/MRI are shown as $55.7 \%, 91.8 \%$, $80.6 \%, 77.2 \%, 78.1 \%$ and $60.8 \%, 94.3 \%, 86.8 \% 79.8 \%, 83.5 \%$, respectively. ${ }^{68}$ Ga-PSMA PET/MRI has higher sensitivity and specificity compared with mpMRI. However, no statistically significant difference was found $(p=0.464)$. Combined imaging had significantly higher diagnostic accuracy compared with mpMRI and ${ }^{68}$ Ga-PSMA PET/MRI (change in AUC: 0.084 and 0.046, $p<0.001$ and $p=0.028$, respectively), while no statistically significant difference was found between mpMRI and ${ }^{68} \mathrm{Ga}-\mathrm{PSMA}$ PET/MRI (change in AUC: $0.038, p=0.246)$.

\section{Conclusion}

${ }^{68}$ Ga-PSMA PET/MRI had higher clinical diagnostic accuracy in prostate cancer compared with mpMRI. Diagnostic accuracy was significantly increased in the combined use of both imaging modalities.

Key words: Gallium, positron emission tomography, magnetic resonance imaging, prostate specific membrane antigen, prostate cancer

\section{INTRODUCTION}

Prostate cancer is the most common cancer in men according to the Global Burden of Cancer (GLOBOCAN) 2018 data. In cancer-related deaths, it takes second place after lung cancer [1]. Multiparametric magnetic resonance imaging (mpMRI) is defined as the addition of diffusion-weighted imaging (DWI) and dynamic contrast-enhanced imaging (DCI) to classical T2-weighted MRI examination, which is used for diagnosis and local staging in prostate cancer. The Prostate Imaging- Reporting and Data System (PI-RADS) assessment uses a 5-point scale based on the probability that a combination of mpMRI findings at T2-weighted imaging, DWI, and DCI to identify the each lesion in the prostate. While mpMRI has become the standard approach after prior negative biopsy [2], some prostate cancer lesions may be overlooked [3,4]. Therefore, there is clearly still a demand for improved imaging methods to more accurately identify prostate cancer.

Hybrid positron emission tomography (PET) / MRI devices, which clinicians have recently started to use, combine the functional findings of PET with the high tissue contrast of mpMRI and increase the intraprostatic lesion detection rates significantly [5]. Several radiopharmaceuticals including ${ }^{18}$ Fluorine $\left({ }^{18} \mathrm{~F}\right)$-ethyl choline, ${ }^{11}$ Carbon $\left({ }^{11} \mathrm{C}\right)$-Acetate, ${ }^{18} \mathrm{~F}$ - Fluorodeoxyglucose (FDG), fluorocyclobutanecarboxylic acid (FACBC) that have shown promise in prostate cancer imaging have been recently put into use. However, ${ }^{68}$ Gallium prostate membrane specific antigen $\left({ }^{68} \mathrm{Ga}-\mathrm{PSMA}\right)$ is currently the most widely used radiopharmaceutical in PET diagnostic imaging for prostate cancer [6].

The aim of our study is to evaluate the diagnostic accuracy of the ${ }^{68}$ Ga-PSMA PET/MRI and mpMRI by region-based comparison of index tumour localisations using histopathological tumour maps of patients who underwent radical prostatectomy $(\mathrm{RP})$ due to clinically significant prostate cancer.

\section{PATIENTS AND METHODS}

\section{Study Design}

The study included 64 patients who underwent radical prostatectomy after primary staging with mpMRI and ${ }^{68}$ Ga-PSMA PET/MRI, between 2017 and 2019. Clinical (age, total prostate-specific antigen [PSA], type of operation), radiological (length, volume, PI-RADS score, maximum standardised uptake value [SUV $\mathrm{Smax}_{\text {] }}$ of lesions, prostate volume), and pathological (biopsy and prostatectomy International Society of Urological Pathology [ISUP] grade, pathological tumour stage, pathological tumour and prostate volumes) data were recorded. Prostate-specific antigen density (PSAD) was calculated by dividing the total PSA by the prostate 
volume. Patients who received neoadjuvant therapy, whose imaging tests were performed at a different centre, or who had another known history of malignancy were excluded from the study.

\section{Multiparametric MRI}

All patients underwent 3.0 Tesla (T) MRI (Magnetom Verio; Siemens Health Care, Erlangen, Germany) according to Prostate Imaging-Recording and Data System (PI-RADS) version 2 (v2) standards [7]. Sequences including high resolution T2-weighted turbo spin-echo images in three orthogonal planes, DWI, and DCI were evaluated using PI-RADS v2 by two radiologists with 15 years of experience. Details of sequence parameters are summarised in Table 1. Contouring of lesions with a PI-RADS score of [?] 3 were also performed by these radiologists.

\section{${ }^{68}$ Ga PSMA PET/MRI}

No additional preparation was requested from the patients prior to 68Ga-PSMA PET/MRI. PET/MRI was performed on the prostate gland and the entire body simultaneously from the vertex to the toe approximately 50 min after $5 \mathrm{mCi}(185 \mathrm{MBq}) 68(\mathrm{Ga})$-PSMA-11 was injected intravenously. An integrated 3T PET/MR camera (GE Signa PET/MRI; GE Healthcare, Waukesha, WI, USA) with a time-of-flight (TOF) feature was used for PET/MRI. Imaging of the prostate gland was performed in a single-bed position. After the first 16-s localiser image, 18-s axial two-point Dixon 3D T1-weighted gradient echo sequences (GESs) were obtained for anatomical registration and attenuation correction maps based on magnetic resonance (MR) images. Subsequently, sagittal (2 min $29 \mathrm{~s}$ ), axial (3 $\min 29 \mathrm{~s}$ ), and coronal (3 min $27 \mathrm{~s}$ ) high-resolution T2-weighted images were taken. In addition, $5 \min 5 \mathrm{~s} \mathrm{for} \mathrm{b}=50,400$, and $800 \mathrm{~s} / \mathrm{mm} 2$ and $4 \min 5 \mathrm{~s}$ for $\mathrm{b}=50,1400$, and $1800 \mathrm{~s} / \mathrm{mm} 2$ of DWIs were obtained for the prostate gland, respectively. PET data were taken simultaneously during the imaging of the MR sequences. High-resolution imaging for the prostate gland took $20 \mathrm{~min}$. Then the whole-body imaging was performed in a nine bed position with a 3-minute acquisition time per bed position. After the first 60-s localiser image, 18-s axial two-point Dixon 3D T1weighted GESs were obtained at each bed position for anatomical registration and attenuation correction maps based on MR images. In addition, 20-s axial T1-weighted images were taken for each bed position. For the first five bed positions, $1 \mathrm{~min} 34 \mathrm{~s}$ axial DWIs were taken at each bed position. In addition, 33-s coronal T2-weighted imaging was performed for the first, third, and fifth bed positions. Simultaneous PET data was obtained during the imaging of the MR sequences. Dixon MR sequences and PET acquisitions were obtained in the same bed position at the same time to ensure optimal temporal and spatial overlap. MR images were segmented to different tissue types for attenuation correction. Reconstruction of PET images was performed using the ordered subset expectation maximisation (OSEM) protocol (two iterations and 28 subsets), and TOF reconstructed images were obtained. PET/MR images were visually and quantitatively evaluated by a nuclear medicine specialist with 9 years of experience. In the PET-avid lesions, pathological uptake of 68Ga-PSMA-11 was reported with an SUVmax value according to the regional anatomy of the prostate (left/right anterior zone and left/right posterior zone). SUVmax was calculated by drawing a volume of interest automatically over the intraprostatic tumour with the highest 68Ga-PSMA-11 uptake in each patient with PET-avid lesions. Region of interest (ROIs) around PET-avid prostatic tumours were defined as a $42 \%$ isocontour threshold of the SUVmax within the focal lesions. PET data were analysed with only T1-weighted MRI sequence for anatomical correlation.

\section{Pathological Evaluation}

A uropathologist with 15 years of experience analysed all RP specimens. Based on the prostate's regional anatomy, specimens were examined in 3-mm sections in cassettes, starting from the bladder neck and moving towards the prostatic apex, after sampling the apex and bladder neck surgical margins and staining the surgical margins of the prostate. Slices were placed on A4 papers for tumour mapping, and their borders were drawn in pencil. After determining the right, left, anterior and posterior orientation, it was marked counterclockwise starting from 1 . Since whole-mount sectioning could not be made, all transverse sections were divided into four pieces to fit the tissue cassettes, taking into account anterior/posterior and right/left discrimination based on the urethra. Hematoxylin-eosin stained sections were prepared after paraffin tissue 
processing. After tissue sections were examined microscopically, mapping was performed by drawing around the tumour areas on slides. The marked slides were placed on A4 paper according to their locations in the drawn prostate slices during the macroscopic sampling. The tumoural areas identified in the slides were transferred onto A4 paper, and the tumour mapping was completed. Tumour grade groups were reported according to the ISUP 2014 consensus conference[8]. Tumour grade group, tumour diameter, approximate tumour volume, extraprostatic extension, surgical margin and local infiltration status (seminal vesicle and bladder neck), and tumour grade and linear length at the surgical margin, if any, were reported for each tumour. The highest ISUP grade group was determined as the criterion for index lesion selection. The extraprostatic extension was determined as a secondary criterion if there were more than one lesion with the same ISUP grade group. If there were no extraprostatic extensions, the lesion with the largest diameter was determined as the index lesion.

Matching Lesions and Uptakes with Index Tumours

The borders of the lesions in the mpMRI, the pathological uptakes in the ${ }^{68}$ Ga-PSMA PET/MRI, and the index tumour of the specimen were drawn in transverse sections by the radiologist, nuclear medicine specialist, and uropathologist, respectively (Fig. 1). Each expert was blind to other image outside of their field. Diagnostic analysis was performed by dividing the prostate into four anatomic regions as left/right anterior and left/right posterior. A total of 256 anatomic regions were evaluated. The extension of the lesions in mpMRI and the pathological uptake in ${ }^{68} \mathrm{Ga}-\mathrm{PSMA}$ PET/MRI were matched separately for each region of the prostate with the extension of the index tumour into each region.

\section{Statistical Analysis}

The sensitivity, specificity, positive predictive value (PPV), negative predictive value (NPV), positive likelihood ratio (PLR), negative likelihood ratio (NLR), and the accuracy of mpMRI ${ }^{68} \mathrm{Ga-PSMA} \mathrm{PET} / \mathrm{MRI}$, and combined imaging for the detection of the index tumour were calculated by creating crosstabs. Correlations between continuous measures were determined using Spearman's $\left(\mathrm{r}_{\mathrm{s}}\right)$ correlation. The Cohen's kappa coefficient $(x)$ was calculated to define agreement between mpMRI and 68(Ga)-PSMA PET/MRI. The cutoff values of clinical parameters were determined by using receiver operating characteristics (ROC) curve analysis and Youden's index. Diagnostic accuracy of imaging modalities was assessed using the area under the curve (AUC), and $95 \%$ confidence intervals (95\% CI) were calculated by ROC analysis. Combined imaging was also added to the ROC analysis as a third method. Accordingly, if either imaging modalities were positive, then the combined imaging was considered positive, and if both imaging modalities were negative, then the combined imaging considered negative. Differences in the sensitivity and specificity of mpMRI and ${ }^{68}$ Ga-PSMA PET/MRI were analysed using the McNemar test. A significance level of $5 \%$ was used. All analyses were performed using SPSS software, version 15.0 (SPSS Inc., Chicago, IL, USA).

\section{Ethics approval}

The study protocol was approved by the Clinical Research Ethics Committee of Gazi University School of Medicine (No. 261, date: December 9, 2019). This study is reproduced from the medical specialty thesis.

\section{RESULTS}

Clinical and pathological features of the patients are summarised in Table 2. A total of 64 patients were included in the study. All patients underwent both mpMRI and ${ }^{68}$ Ga-PSMA PET/MRI. In eight patients, no lesion was observed in the mpMRI, and in eight patients, no pathological uptake was observed in the ${ }^{68}$ Ga-PSMA PET/MRI. In one patient, neither lesion nor pathological uptake was observed in imaging.

Correlation analyses were performed between lesion length and lesion volume and between PSAD and $\mathrm{SUV}_{\max }$. A strong correlation was found between lesion length and lesion volume, while there was a moderate correlation between PSAD and $\mathrm{SUV}_{\max }\left(\mathrm{r}_{\mathrm{s}}=0.66, p<0.001 ; \mathrm{r}_{\mathrm{s}}=0.32, p<0.001\right.$, respectively). Regarding the agreement between mpMRI and ${ }^{68} \mathrm{Ga}$-PSMA PET/MRI in identifying the index tumour, the Cohen's kappa coefficient $(x)$ was $0.505 \pm 0.56$, indicating moderate agreement. 
The sensitivity, specificity, PPV, NPV, PLR, NLR, and the accuracy of mpMRI, 68(Ga)-PSMA PET/MRI, and combined imaging are shown in Table 3. Combined imaging had significantly higher diagnostic accuracy compared with mpMRI and ${ }^{68} \mathrm{Ga}$-PSMA PET/MRI (change in AUC: 0.084 and $0.046, p<0.001$ and $p$ $=0.028$, respectively), while no statistically significant difference was found between mpMRI and $68(\mathrm{Ga})$ PSMA PET/MRI (change in AUC: $0.38, p=0.246$ ) (Fig. 2). Moreover, ${ }^{68}$ Ga-PSMA PET/MRI has higher sensitivity and specificity rates compared with mpMRI. However, no statistically significant difference was found $(p=0.464)$.

Patients were separated into two groups according to the tumour pathology (ISUP $<3$ and ISUP [?] 3), and then the cut-off values of $\mathrm{SUV}_{\max }$, total PSA, PSAD, lesion length, and lesion volume were determined at points with optimal specificity and sensitivity via ROC curves generated in predicting advanced tumour ISUP grade. Optimal cut-off values were found to be $10 \mathrm{ng} / \mathrm{ml}$ for total PSA (AUC [CI 95\%] $=0.64[0.50-$ $0.78]$ ), $0.18 \mathrm{ng} / \mathrm{ml} / \mathrm{ml}$ for PSAD (AUC [CI 95\%] $=0.67$ [0.54-0.80]), $1.5 \mathrm{ml}$ for lesion volume (AUC [CI 95\%] $=0.69[0.55-0.83]), 15 \mathrm{~mm}$ for lesion length $(\mathrm{AUC}$ [CI 95\%] $=0.70[0.56-0.84])$, and 7.1 for $\mathrm{SUV}_{\max }(\mathrm{AUC}$ [CI 95\%] $=0.70[0.57-0.83])$.

The sensitivity and specificity of mpMRI, ${ }^{68} \mathrm{Ga}$-PSMA PET/MRI and combined imaging according to the subgroups of total PSA, PSAD, lesion length, lesion volume, and $\mathrm{SUV}_{\max }$ are shown in Table 4. It was seen that the sensitivity of the mpMRI and ${ }^{68}$ Ga-PSMA PET/MRI in the high total PSA, high PSAD, high PI-RADS score, high lesion length, and high lesion volume groups increased. The specificity of mpMRI was also increased in the high total PSA and high PSAD groups. The sensitivity of ${ }^{68}$ Ga-PSMA PET/MRI also increased in the high $\mathrm{SUV}_{\max }$ group. In the ROC analysis performed by evaluating AUC changes for all imaging methods, no significant difference was found between any subgroups in terms of diagnostic accuracy.

\section{DISCUSSION}

In clinical localised prostate cancer, $67 \%$ to $87 \%$ of the tumours are detected multifocally at the time of diagnosis. The index tumour, which is the lesion with the highest Gleason score or the highest volume, is the determinant for the prognosis $[9,10]$. Therefore, it is crucial to detect the index tumour even in multifocal disease.

Besides the local staging of prostate cancer, the first steps towards identifying index tumours have also started with the increasing use of mpMRI. In a meta-analysis including 9796 patients, pooled data for extraprostatic extension, seminal vesicle invasion and overall stage T3 detection showed sensitivity and specificity of $57 \%$ and $91 \%, 58 \%$ and $96 \%$, and $61 \%$ and $81 \%$ for mpMRI, respectively [11] Contrary to local staging data, in a Cochrane meta-analysis which compared mpMRI to template biopsies in biopsy-naive and repeat-biopsy settings, mpMRI had a pooled sensitivity of $91 \%$ and a pooled specificity of $37 \%$ for ISUP grade $>2$ cancers, and had a pooled sensitivity of $95 \%$ and a pooled specificity of $35 \%$ for ISUP grade $>3$ cancers, respectively [12]. Jesse et al. examined the RP specimens of 122 patients and found the lesion-based sensitivity of mpMRI to be $47 \%$. It was demonstrated that the sensitivity of mpMRI was $72 \%$ for lesions of $>1 \mathrm{~cm}$ and $72 \%$ for tumours with an ISUP grade group of [?] 2 in subgroup analysis. The sensitivity of mpMRI was also found to be related to tumour size, Gleason grade, and prostate volume [13]. In our study, high volume and PI-RADS score of the lesion, high PSA, and high PSAD were found to increase the sensitivity of mpMRI, although this was not statistically significant.

Hartenbach et al. [14] designed a prospective, lesion-based study in which 128 lesions were assessed side by side after matching the angulation of the histological step sections and the MRI slices using PET with ${ }^{18} \mathrm{~F}$ ethyl choline combined with endorectal MRI. Assessments were correlated with the histologically dot-marked tumour lesions. Sensitivities and specificities, respectively, were found to be $48 \%$ and $40 \%$ for endorectal MRI, $71 \%$ and $42 \%$ for ${ }^{18} \mathrm{~F}$-ethyl choline PET, and $66 \%$ and $82 \%$ for combined ${ }^{18} \mathrm{~F}$-ethyl choline PET and endorectal MRI. Combined ${ }^{18}$ F-ethyl choline PET and endorectal MRI had significantly higher diagnostic accuracy compared with the individual modalities.

In studies investigating the diagnostic accuracy of PET/MRI in the literature, we see that there are many differences in terms of the methodology and radiotracer used. Albayati et al. used a lesion-based approach in 
a study including 22 patients with 41 lesions. They created two models of dichotomisation for the calculation of lesion-based sensitivities and specificities using transrectal biopsy and RP specimens. The results were dichotomised by defining as malignant either a PI-RADS score of 4-5 and a PET score of 4-5 or a PI-RADS score of 3-5 and a PET score of 3-5. Sensitivities and specificities, respectively, of mpMRI and ${ }^{68}$ Ga-PSMA PET/MRI were $59 \%$ vs $88 \%$ and $67 \%$ vs $100 \%$ for dichotomisation scores $1-3$ vs $4-5$ and $94 \%$ vs $94 \%$ and $23 \%$ vs $56 \%$ for dichotomisation scores $1-2$ vs $3-5$ [15].

Table 5 summarises the studies in which region-based evaluations were applied in terms of evaluated regions per patient, PET/MRI tracers in terms of sensitivities and specificities of mpMRI and PET/MRI [5,1620]. Radical prostatectomy specimens were used for histopathological evaluation in all these studies. The evaluation was performed by simply dividing the prostate into regions, except for in the study designed by Hicks et al. who used two different 30-region-based approaches. In addition to the simple regionbased approach known as 'raw stringent', Hicks et al. used radiological-pathological correlation, which was classified as tumour being present in the same region or any of the immediately adjacent regions, known as the 'neighbouring approach'. Hicks et al. found that ${ }^{68}$ Ga-PSMA PET/MRI was significantly superior to the mpMRI in terms of sensitivity in both raw stringent and neighbouring approaches $(67 \%$ vs $42 \%$ and $74 \%$ vs $50 \%$, respectively). The mpMRI was significantly superior to the ${ }^{68}$ Ga-PSMA PET/MRI in terms of specificity using the raw stringent approach $(79 \%$ vs $71 \%$, respectively). However, there was no significant difference in terms of specificity using the neighbouring approach (90\% vs $88 \%$, respectively) [18].

In our study, which was a simple four-region-based study, ${ }^{68}$ Ga-PSMA PET/MRI had higher sensitivity and specificity compared with mpMRI, although this was not statistically significant ( $60.8 \%$ vs $55.7 \%$ and $94.3 \%$ vs $91.8 \%$, respectively). However, combined imaging had significantly higher diagnostic accuracy compared with ${ }^{68} \mathrm{Ga}$-PSMA PET/MRI and mpMRI (change in AUC: 0.084 and $0.046, p<0.001$ and $p=0.028$, respectively). In the study by Hicks et al., the tumours, which were detected with an $\mathrm{SUV}_{\max }$ of [?] 6.9 on ${ }^{68} \mathrm{Ga}$-PSMA PET/MRI, had a Gleason score of [?]7 [18]. In our study, we determined the cut-off value for $\mathrm{SUV}_{\max }$ to be 7.1 in predicting a Gleason score of [?] 7. However, there were two patients, who had a Gleason score of $3+3$, with an $\mathrm{SUV}_{\max }$ of 9.5 and 12 .

In a study conducted by Lee et al., PET/MRI was performed using both ${ }^{18} \mathrm{~F}$ - FDG and ${ }^{18} \mathrm{~F}$-choline as radiotracers. Using a six-region-based approach, it was shown that ${ }^{18} \mathrm{~F}$-choline PET/MRI had higher sensitivity and specificity compared with ${ }^{18}$ F-FDG PET/MRI [17]. Eiber et al., who designed a six-region-based evaluation study, showed that both mpMRI and ${ }^{68}$ Ga-PSMA PET/MRI had significantly better diagnostic performance in large tumours $(>5 \mathrm{~mm})$ compared with small tumours ([?]5 $\mathrm{mm})$ [5]. In our study, we observed that the sensitivity increased using both methods with a lesion size of $>15 \mathrm{~mm}$ and lesion volume of $>1.5$ $\mathrm{ml}$, and this increase was more prominent in ${ }^{68}$ Ga-PSMA PET/MRI. However, we did not find a statistically significant difference between the lesion size and lesion volume groups in terms of diagnostic accuracy for both imaging modalities. Eiber et al. also showed that mpMRI had higher sensitivity in PI-RADS 3 lesions compared with ${ }^{68}$ Ga-PSMA PET/MRI [5]. Contrary to this finding, in our study, ${ }^{68}$ Ga-PSMA PET/MRI had higher sensitivity in PI-RADS 3 lesions compared with mpMRI ( $34.5 \%$ vs $55.2 \%$, respectively). In combined usage, we showed that sensitivities increased significantly in terms of all parameters.

In a meta-analysis by Li et al., which included nine studies and 353 patients, PET/MRI had significantly higher diagnostic accuracy compared with mpMRI. Sensitivities were found to be $60 \%$ vs $78 \%$ and specificities to be $90 \%$ vs $88 \%$ for mpMRI and PET/MRI, respectively. However, when considering the results of this meta-analysis, it should be noted that lesion-based and region-based studies using different radiotracers were evaluated together [21].

Limitations

Our study was retrospective, non-randomised, and conducted at a single centre. As ${ }^{68}$ Ga-PSMA PET/MRI is a relatively new method in Turkey, the number of patients undergoing this imaging is still low. Moreover, our trial included patients from 2017, when we used PI-RADS v2, not the current version. Whereas we used a region-based approach to evaluate the diagnostic accuracy of imaging modalities, a three-dimensional 
lesion-based approach could be used for a more accurate assessment in future studies.

\section{CONCLUSION}

In our study, we showed that ${ }^{68}$ Ga-PSMA PET/MRI had higher clinical diagnostic accuracy in identifying index tumour of prostate cancer compared with mpMRI. Diagnostic accuracy was significantly increased in the combined use of both imaging modalities. In prospective, lesion-based studies involving more patients, we think that more significant results can be obtained to support our results. The combined use of both methods seems to be more rational in terms of determining the index tumour and the guidance of focal ablative therapies.

\section{Funding}

This research received no specific grant from any funding agency in the public, commercial, or not-for-profit sectors.

\section{Conflicts of interest}

The authors have no conflicts of interest to declare.

\section{REFERENCES}

1. Ferlay J, Colombet M, Soerjomataram I, et al. Estimating the global cancer incidence and mortality in 2018: GLOBOCAN sources and methods.Int J Cancer . 2019;144(8):1941-1953.

2. European association U [European Association of Urology guidelines]. Edition. Vol. presented at the EAU Annual Congress Amsterdam; 2020. Arnhem, The Netherlands: European Association of Urology Guidelines Office:2020.

3. Reisaeter LA, Futterer JJ, Halvorsen OJ, et al. 1.5-T multiparametric MRI using PI-RADS: a region by region analysis to localize the index-tumor of prostate cancer in patients undergoing prostatectomy.Acta radiol . 2015;56(4):500-511.

4. Hoeks CM, Hambrock T, Yakar D, et al. Transition zone prostate cancer: detection and localization with 3-T multiparametric MR imaging. Radiology . 2013;266(1):207-217.

5. Eiber M, Weirich G, Holzapfel K, et al. Simultaneous 68Ga-PSMA HBED-CC PET/MRI improves the localization of primary prostate cancer.Eur Urol . 2016;70(5):829-836.

6. Hoffmann MA, Wieler HJ, Baues C, Kuntz NJ, Richardsen I, Schreckenberger M. The impact of 68GaPSMA PET/CT and PET/MRI on the management of prostate cancer. Urology . 2019;130:1-12.

7. Weinreb JC, Barentsz JO, Choyke PL, et al. PI-RADS Prostate Imaging-Reporting and Data System ; 2015, version 2. European urology. 2016; vol 69(1):16-40.

8. Epstein JI, Egevad L, Amin MB, et al. The 2014 International Society of Urological Pathology (ISUP) consensus conference on Gleason grading of prostatic carcinoma: Definition of Grading Patterns and Proposal for a New Grading System. Am J Surg Pathol . 2016;40(2):244-252.

9. Perera M, Lawrentschuk N, Bolton D, Clouston D. Comparison of contemporary methods for estimating prostate tumour volume in pathological specimens. BJU Int . 2014;113(suppl 2):29-34.

10. Arora R, Koch MO, Eble JN, et al. Heterogeneity of Gleason grade in multifocal adenocarcinoma of the prostate. Cancer: interdisciplinary. Int J Am Cancer Society. 2004;100(11):2362-2366.

11. de Rooij M, Hamoen EH, Witjes JA, Barentsz JO, Rovers MM. Accuracy of magnetic resonance imaging for local staging of prostate cancer: a diagnostic meta-analysis. Eur Urol . 2016;70(2):233245.

12. Drost FH, Osses DF, Nieboer D, et al. Prostate MRI, with or without MRI-targeted biopsy, and systematic biopsy for detecting prostate cancer. Cochrane Database Syst Rev . 2019;4:CD012663.

13. Le JD, Tan N, Shkolyar E, et al. Multifocality and prostate cancer detection by multiparametric magnetic resonance imaging: correlation with whole-mount histopathology. Eur Urol . 2015;67(3):569576.

14. Hartenbach M, Hartenbach S, Bechtloff W, et al. Combined PET/MRI improves diagnostic accuracy in patients with prostate cancer: a prospective diagnostic trial. Clin Cancer Res . 2014;20(12):3244-3253. 
15. Al-Bayati M, Grueneisen J, Lutje S, et al. Integrated 68gallium labelled prostate-specific membrane antigen-11 positron emission tomography/magnetic resonance imaging enhances discriminatory power of multi-parametric prostate magnetic resonance imaging. Urol Int . 2018;100(2):164-171.

16. de Perrot T, Rager O, Scheffler M, et al. Potential of hybrid 18 F-fluorocholine PET/MRI for prostate cancer imaging. Eur J Nucl Med Mol Imaging . 2014;41(9):1744-1755.

17. Lee MS, Cho JY, Kim SY, et al. Diagnostic value of integrated PET/MRI for detection and localization of prostate cancer: comparative study of multiparametric MRI and PET/CT. J Magn Reson Imaging . 2017;45(2):597-609.

18. Hicks RM, Simko JP, Westphalen AC, et al. Diagnostic accuracy of 68Ga-PSMA-11 PET/MRI compared with multiparametric MRI in the detection of prostate cancer. Radiology . 2018;289(3):730-737.

19. Jambor I, Kuisma A, Kahkonen E, et al. Prospective evaluation of 18 F-FACBC PET/CT and PET/MRI versus multiparametric MRI in intermediate-to high-risk prostate cancer patients (FLUCIPRO trial).Eur J Nucl Med Mol Imaging . 2018;45(3):355-364.

20. Park SY, Zacharias C, Harrison C, et al. Gallium 68 PSMA-11 PET/MR imaging in patients with intermediate- or high-risk prostate cancer.Radiology . 2018;288(2):495-505.

21. Li M, Huang Z, Yu H, Wang Y, Zhang Y, Song B. Comparison of PET/MRI with multiparametric MRI in diagnosis of primary prostate cancer: A meta-analysis. Eur J Rad . 2019;113:225-231.

TABLES

Table 1. Sequence parameters for multiparametric magnetic resonance imaging

\begin{tabular}{llll}
\hline & T2-weighted images & $\begin{array}{l}\text { Diffusion-weighted } \\
\text { images }\end{array}$ & $\begin{array}{l}\text { Dynamic } \\
\text { contrasted-enhanced } \\
\text { images }\end{array}$ \\
$\begin{array}{llll}\text { Field of view } \\
\text { (millimetres) }\end{array}$ & $200 \times 200$ & $240 \times 240$ & $240 \times 240$ \\
$\begin{array}{l}\text { Matrix } \\
\text { (millimetres) }\end{array}$ & $512 \times 512$ & $256 \times 256$ & $160 \times 160$ \\
$\begin{array}{l}\text { Repetition time } \\
\text { (milliseconds) }\end{array}$ & $2800-3000$ & 3500 & 5,3 \\
$\begin{array}{l}\text { Echo time } \\
\text { (milliseconds) }\end{array}$ & 100 & 90 & 1,8 \\
$\begin{array}{l}\text { Flip angle (degrees) } \\
\text { Thickness }\end{array}$ & 150 & 90 & 15 \\
$\begin{array}{l}\text { (millimetres) (no } \\
\text { gap) }\end{array}$ & 3 & 4 & 3,6 \\
$\begin{array}{l}\text { B value } \\
\text { (seconds/millimetre }\end{array}$ & Not applicable & $400,1000,1400$ & Not applicable \\
$\begin{array}{l}\text { square) } \\
\text { Averages (number } \\
\text { of excitations) }\end{array}$ & 4 & 4 & 1 \\
$\begin{array}{l}\text { Echo train length } \\
\text { Acquisition time } \\
\text { (minutes + seconds) } \\
\begin{array}{l}\text { Temporal resolution } \\
\text { (seconds) }\end{array}\end{array}$ & Not applicable & 1 & 1 \\
\hline
\end{tabular}

Table 2. Clinical and pathological features of the patients

Age (year) $($ mean $\pm \mathrm{SD})$

Total PSA (ng/ml) [median (range)] 
Prostate volume $(\mathrm{ml})$ [median (range)]

PSA density $(\mathrm{ng} / \mathrm{ml} / \mathrm{ml}$ ) [median (range)]

Lesion length $(\mathrm{mm})$ [median (range)]

Lesion volume $(\mathrm{ml})$ [median (range)]

PI-RADS score n (\%)

2

3

4

5

SUVmax [median (range)]

Type of operation n (\%)

Open radical prostatectomy

Robotic radical prostatectomy

Radical prostatectomy pathological grade

ISUP 1

ISUP 2

ISUP 3

ISUP 4

ISUP 5

Tumour stage n (\%)

pT2

pT3a

pT3b

Pathological prostate volume (ml) [median (range)]

Pathological tumour volume (ml) [median (range)]

Abbreviations. PSA: prostate specific antigen. SD: standard deviation. SUV: standard uptake value. PI-RADS: Prostate

Table 3. Diagnostic value of multiparametric MRI and ${ }^{68}$ Ga-PSMA PET/MRI in detecting index tumour of prostate cancer.

\begin{tabular}{|c|c|c|c|c|c|c|c|c|}
\hline & SEN (\%) & SPE (\%) & PPV (\%) & NPV (\%) & $\operatorname{PLR}(\%)$ & NLR (\%) & $\begin{array}{l}\text { Accuracy } \\
(\%)\end{array}$ & $p$ valu \\
\hline \multicolumn{2}{|c|}{$\begin{array}{l}\text { Multiparametr5.5,7 } \\
\text { MRI }\end{array}$} & 91,8 & 80,6 & 77,2 & 6,7 & 2,0 & 78,1 & \multirow[t]{3}{*}{$0.464^{*}$} \\
\hline $\begin{array}{l}68(\mathrm{Ga})- \\
\text { PSMA } \\
\text { PET/MRI }\end{array}$ & 60,8 & 94,3 & 86,8 & 79,8 & 10,6 & 2,4 & 81,6 & \\
\hline $\begin{array}{l}\text { Combined } \\
\text { Imaging }\end{array}$ & 76,3 & 88,1 & 79,6 & 85,9 & 6,4 & 3,7 & 83,5 & \\
\hline
\end{tabular}

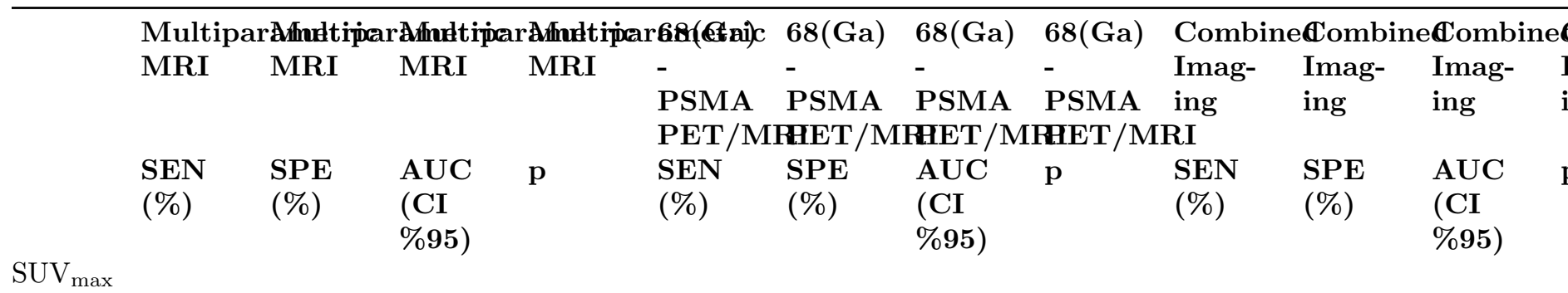




\begin{tabular}{|c|c|c|c|c|c|c|c|c|c|c|c|}
\hline \multicolumn{5}{|l|}{$<7.1$} & 52,6 & 95,6 & $\begin{array}{l}0,73 \\
(0,64- \\
0,82)\end{array}$ & 0,83 & & & \\
\hline \multicolumn{5}{|l|}{ [?] 7.1} & 72,5 & 92,6 & $\begin{array}{l}0,74 \\
(0,64- \\
0,85)\end{array}$ & & & & \\
\hline \multicolumn{12}{|l|}{$\begin{array}{l}\text { Total } \\
\text { PSA } \\
(\mathrm{ng} / \mathrm{ml})\end{array}$} \\
\hline$<10$ & 49,2 & 90,7 & $\begin{array}{l}0,69 \\
(0,61- \\
0,78)\end{array}$ & 0,09 & 60 & 96,3 & $\begin{array}{l}0,78 \\
(0,70- \\
0,86)\end{array}$ & 0,81 & 72,3 & 88,8 & $\begin{array}{l}0,80 \\
(0,73- \\
0,87)\end{array}$ \\
\hline [?]10 & 68,8 & 94,2 & $\begin{array}{l}0,81 \\
(0,71- \\
0,92)\end{array}$ & & 62,5 & 90,4 & $\begin{array}{l}0,76 \\
(0,65- \\
0,87)\end{array}$ & & 84,4 & 86,5 & $\begin{array}{l}0,85(0,76- \\
0,94)\end{array}$ \\
\hline \multicolumn{12}{|c|}{$\begin{array}{l}\text { PSAD } \\
(\mathrm{ng} / \mathrm{ml} / \mathrm{m})\end{array}$} \\
\hline$<0,18$ & 50,9 & 88,9 & $\begin{array}{l}0,70 \\
(0,61- \\
0,79)\end{array}$ & 0,22 & 54,5 & 95,1 & $\begin{array}{l}0,75 \\
(0,66- \\
0,83)\end{array}$ & 0,32 & 74,5 & 85,2 & $\begin{array}{l}0,80 \\
(0,72- \\
0,88)\end{array}$ \\
\hline$[?] \quad 0,18$ & 61,9 & 94,9 & $\begin{array}{l}0,78 \\
(0,69- \\
0,88)\end{array}$ & & 69,0 & 93,6 & $\begin{array}{l}0,81 \\
(0,72- \\
0,91)\end{array}$ & & 78,6 & 91,0 & $\begin{array}{l}0,85 \\
(0,77- \\
0,93)\end{array}$ \\
\hline \multicolumn{12}{|l|}{$\begin{array}{l}\text { PI- } \\
\text { RADS } \\
\text { score }\end{array}$} \\
\hline [?] 3 & 34,5 & 94,9 & $\begin{array}{l}0,64 \\
(0,50- \\
0,70)\end{array}$ & 0,10 & 55,2 & 94,9 & $\begin{array}{l}0,75 \\
(0,63- \\
0,88)\end{array}$ & 0,62 & 65,5 & 89,7 & $\begin{array}{l}0,78 \\
(0,66- \\
0,90)\end{array}$ \\
\hline [?] 4 & 64,7 & 90,8 & $\begin{array}{l}0,77 \\
(0,70- \\
0,85)\end{array}$ & & 63,2 & 94,2 & $\begin{array}{l}0,79 \\
(0,71- \\
0,86)\end{array}$ & & 80,0 & 87,5 & $\begin{array}{l}0,84 \\
(0,78- \\
0,91)\end{array}$ \\
\hline \multicolumn{12}{|c|}{$\begin{array}{l}\text { Lesion } \\
\text { volume(ml) }\end{array}$} \\
\hline$<1.5$ & 54,5 & 92,5 & $\begin{array}{l}0,74 \\
(0,64- \\
0,84)\end{array}$ & 0,96 & 54,5 & 96,3 & $\begin{array}{l}0,75 \\
(0,66- \\
0,85)\end{array}$ & 0,56 & 77,3 & 88,8 & $\begin{array}{l}0,83 \\
(0,75- \\
0,91)\end{array}$ \\
\hline [?]1.5 & 56,6 & 91,1 & $\begin{array}{l}0,74 \\
(0,65- \\
0,83)\end{array}$ & & 66,0 & 92,4 & $\begin{array}{l}0,79 \\
(0,71- \\
0,88)\end{array}$ & & 75,5 & 87,3 & $\begin{array}{l}0,81 \\
(0,73- \\
0,89)\end{array}$ \\
\hline \multicolumn{12}{|c|}{$\begin{array}{l}\text { Lesion } \\
\text { length(mm) }\end{array}$} \\
\hline$<15 \mathrm{~mm}$ & 54,5 & 94,8 & $\begin{array}{l}0,74 \\
(0,65- \\
0,83)\end{array}$ & 0,71 & 54,5 & 95,9 & $\begin{array}{l}0,75 \\
(0,66- \\
0,84)\end{array}$ & 0,42 & 74,5 & 90,7 & $\begin{array}{l}0,83 \\
(0,75- \\
0,90)\end{array}$ \\
\hline [?]15mm & 57,1 & 87,1 & $\begin{array}{l}0,72 \\
(0,61- \\
0,82)\end{array}$ & & 69,0 & 91,9 & $\begin{array}{l}0,81 \\
(0,71- \\
0,90)\end{array}$ & & 78,6 & 83,9 & $\begin{array}{l}0,81 \\
(0,72- \\
0,90)\end{array}$ \\
\hline
\end{tabular}




\begin{tabular}{|c|c|c|c|c|c|c|c|c|c|c|c|}
\hline MRI: & MRI: & MRI: & MRI: & MRI: & MRI: & MRI: & MRI: & MRI: & MRI: & MRI: & MRI: \\
\hline mag- & mag- & mag- & mag- & mag- & mag- & mag- & mag- & mag- & mag- & mag- & mag- \\
\hline netic & netic & netic & netic & netic & netic & netic & netic & netic & netic & netic & netic \\
\hline reso- & reso- & reso- & reso- & reso- & reso- & reso- & reso- & reso- & reso- & reso- & eso- \\
\hline nance & nance & nance & nance & nance & nance & nance & nance & nance & nance & nance & nance \\
\hline imag- & imag- & imag- & imag- & imag- & imag- & imag- & imag- & imag- & imag- & imag- & imag- \\
\hline ing, & ing, & ing, & ing, & ing, & ing, & ing, & ing, & ing, & ing, & ing, & ing, \\
\hline $68(\mathrm{Ga}):$ & $68(\mathrm{Ga}):$ & $68(\mathrm{Ga}):$ & $68(\mathrm{Ga}):$ & $68(\mathrm{Ga}):$ & $68(\mathrm{Ga}):$ & $68(\mathrm{Ga}):$ & $68(\mathrm{Ga}):$ & $68(\mathrm{Ga}):$ & $68(\mathrm{Ga}):$ & $68(\mathrm{Ga}):$ & $68(\mathrm{Ga}):$ \\
\hline Galium- & Galium- & Galium- & Galium- & Galium- & Galium- & Galium- & Galium- & Galium- & Galium- & Galium- & Galium- \\
\hline 68 & 68 & 68 & 68 & 68 & 68 & 68 & 68 & 68 & 68 & 68 & 68 \\
\hline PSMA: & PSMA: & PSMA: & PSMA: & PSMA: & PSMA: & PSMA: & PSMA: & PSMA: & PSMA: & PSMA: & PSMA: \\
\hline prostate & prostate & prostate & prostate & prostate & prostate & prostate & prostate & prostate & prostate & prostate & prostate \\
\hline spe- & spe- & spe- & spe- & spe- & spe- & spe- & spe- & spe- & spe- & spe- & spe- \\
\hline cific & cific & cific & cific & cific & cific & cific & cific & cific & cific & cific & cific \\
\hline mem- & mem- & mem- & mem- & mem- & mem- & mem- & mem- & mem- & mem- & mem- & mem- \\
\hline $\begin{array}{l}\text { orane } \\
\text { anti- }\end{array}$ & $\begin{array}{l}\text { Drane } \\
\text { anti- }\end{array}$ & anti- & anti- & $\begin{array}{l}\text { orane } \\
\text { anti- }\end{array}$ & $\begin{array}{l}\text { orane } \\
\text { anti- }\end{array}$ & $\begin{array}{l}\text { orane } \\
\text { anti- }\end{array}$ & $\begin{array}{l}\text { Drane } \\
\text { anti- }\end{array}$ & $\begin{array}{l}\text { orane } \\
\text { anti- }\end{array}$ & anti- & anti- & $\begin{array}{l}\text { orane } \\
\text { anti- }\end{array}$ \\
\hline gen & gen & gen & gen & gen & gen & gen & gen & gen & gen & gen & gen \\
\hline PET: & PET: & PET: & PET: & PET: & PET: & PET: & PET: & PET: & PET: & PET: & PET: \\
\hline positron & positron & positron & positron & positron & positron & positron & positron & positron & positron & positron & positron \\
\hline $\begin{array}{l}\text { emis- } \\
\text { sion }\end{array}$ & $\begin{array}{l}\text { emis- } \\
\text { sion }\end{array}$ & $\begin{array}{l}\text { emis- } \\
\text { sion }\end{array}$ & $\begin{array}{l}\text { emis- } \\
\text { sion }\end{array}$ & $\begin{array}{l}\text { emis- } \\
\text { sion }\end{array}$ & $\begin{array}{l}\text { emis- } \\
\text { sion }\end{array}$ & $\begin{array}{l}\text { emis- } \\
\text { sion }\end{array}$ & $\begin{array}{l}\text { emis- } \\
\text { sion }\end{array}$ & $\begin{array}{l}\text { emis- } \\
\text { sion }\end{array}$ & $\begin{array}{l}\text { emis- } \\
\text { sion }\end{array}$ & $\begin{array}{l}\text { emis- } \\
\text { sion }\end{array}$ & $\begin{array}{l}\text { emis- } \\
\text { sion }\end{array}$ \\
\hline to- & to- & to- & to- & to- & to- & to- & to- & to- & to- & to- & to- \\
\hline mog- & mog- & mog- & mog- & mog- & mog- & mog- & mog- & mog- & mog- & mog- & mog- \\
\hline ra- & ra- & ra- & ra- & ra- & ra- & ra- & ra- & ra- & ra- & ra- & ra- \\
\hline phy, & phy, & phy, & phy, & phy, & phy, & phy, & phy, & phy, & phy, & phy, & phy, \\
\hline $\mathrm{SUV}_{\max }$ & $\mathrm{SUV}_{\max }$ & $\mathrm{SUV}_{\max }$ & $\mathrm{SUV}_{\max }$ & $\mathrm{SUV}_{\max }$ & $\mathrm{SUV}_{\max }$ & $\mathrm{SUV}_{\max }$ & $\mathrm{SUV}_{\max }$ & $\mathrm{SUV}_{\max }$ & $\mathrm{SUV}_{\max }$ & $\mathrm{SUV}_{\max }$ & $\mathrm{SUV}_{\max }$ \\
\hline : & : & : & $:$ & $:$ & $:$ & : & : & : & $:$ & $:$ & : \\
\hline $\max -$ & $\max -$ & $\max -$ & $\max -$ & $\max -$ & $\max -$ & $\max -$ & $\max -$ & $\max -$ & $\max -$ & $\max -$ & $\max -$ \\
\hline i- & i- & i- & i- & i- & i- & i- & i- & i- & i- & i- & i- \\
\hline mum & mum & mum & mum & mum & mum & mum & mum & mum & mum & mum & mum \\
\hline stan- & stan- & stan- & stan- & stan- & stan- & stan- & stan- & stan- & stan- & stan- & stan- \\
\hline dard- & dard- & dard- & dard- & dard- & dard- & dard- & dard- & dard- & dard- & dard- & dard- \\
\hline ised & ised & ised & ised & ised & ised & ised & ised & ised & ised & ised & ised \\
\hline up- & up- & up- & up- & up- & up- & up- & up- & up- & up- & up- & up- \\
\hline take & take & take & take & take & take & take & take & take & take & take & take \\
\hline value, & value, & value, & value, & value, & value, & value, & value, & value, & value, & value, & value, \\
\hline PSA: & PSA: & PSA: & PSA: & PSA: & PSA: & PSA: & PSA: & PSA: & PSA: & PSA: & PSA: \\
\hline prostate & prostate & prostate & prostate & prostate & prostate & prostate & prostate & prostate & prostate & prostate & prostate \\
\hline spe- & spe- & spe- & spe- & spe- & spe- & spe- & spe- & spe- & spe- & spe- & spe- \\
\hline cific & cific & cific & cific & cific & cific & cific & cific & cific & cific & cific & cific \\
\hline anti- & anti- & anti- & anti- & anti- & anti- & anti- & anti- & anti- & anti- & anti- & anti- \\
\hline gen, & gen, & gen, & gen, & gen, & gen, & gen, & gen, & gen, & gen, & gen, & gen, \\
\hline SEN: & SEN: & SEN: & SEN: & SEN: & SEN: & SEN: & SEN: & SEN: & SEN: & SEN: & SEN: \\
\hline sen- & sen- & sen- & sen- & sen- & sen- & sen- & sen- & sen- & sen- & sen- & sen- \\
\hline sitiv- & sitiv- & sitiv- & sitiv- & sitiv- & sitiv- & sitiv- & sitiv- & sitiv- & sitiv- & sitiv- & sitiv- \\
\hline ity, & ity, & ity, & ity, & ity, & ity, & ity, & ity, & ity, & ity, & ity, & ity, \\
\hline SPE: & SPE: & SPE: & SPE: & SPE: & SPE: & SPE: & SPE: & SPE: & SPE: & SPE: & SPE: \\
\hline speci- & speci- & speci- & speci- & speci- & speci- & speci- & speci- & speci- & speci- & speci- & speci- \\
\hline ficity, & ficity, & ficity, & ficity, & ficity, & ficity, & ficity, & ficity, & ficity, & ficity, & ficity, & ficity, \\
\hline AUC: & AUC: & AUC: & AUC: & AUC: & AUC: & AUC: & AUC: & AUC: & AUC: & AUC: & AUC: \\
\hline area & area & area & area & area & area & area & area & area & area & area & area \\
\hline un- & un- & un- & un- & un- & $\mathrm{up}_{\overline{1}}$ & un- & un- & un- & un- & un- & un- \\
\hline der & der & der & der & der & der & der & der & der & der & der & der \\
\hline curve, & curve, & curve, & curve, & curve, & curve, & curve, & curve, & curve, & curve, & curve, & curve, \\
\hline ROC: & ROC: & ROC: & ROC: & ROC: & ROC: & ROC: & ROC: & ROC: & ROC: & ROC: & ROC: \\
\hline Re- & Re- & Re- & Re- & Re- & Re- & Re- & Re- & Re- & Re- & Re- & Re- \\
\hline oper- & $\begin{array}{l}\text { celver } \\
\text { oper- }\end{array}$ & oper- & oper- & oper- & oper- & oper- & oper- & oper- & oper- & oper- & $\begin{array}{l}\text { celver } \\
\text { oper- }\end{array}$ \\
\hline
\end{tabular}


Table 4. Subgroup analyses of multiparametric MRI, 68(Ga)-PSMA PET/MRI and combined imaging in terms of diagnostic accuracy by performing ROC analysis.

Table 5. The studies about the region-based evaluation of mpMRI and PET/MRI

\begin{tabular}{|c|c|c|c|c|c|c|c|c|}
\hline \multirow[t]{2}{*}{$\begin{array}{l}\text { Study / } \\
\text { Year }\end{array}$} & \multirow[t]{2}{*}{$\begin{array}{l}\text { No. of } \\
\text { Patients }\end{array}$} & \multirow[t]{2}{*}{$\begin{array}{l}\text { Evaluated } \\
\text { region per } \\
\text { patient }\end{array}$} & Radiotracer & mpMRI & \multirow{2}{*}{$\begin{array}{l}\text { mpMRI } \\
\text { SPE } \\
(\%)\end{array}$} & \multirow{2}{*}{$\begin{array}{l}\text { mpMRI } \\
\text { SPE } \\
(\%)\end{array}$} & \multirow{2}{*}{$\begin{array}{l}\text { PET/MRI } \\
\text { SEN } \\
(\%)\end{array}$} & \multirow{2}{*}{$\begin{array}{l}\text { PET/ } \\
\text { SPE } \\
(\%)\end{array}$} \\
\hline & & & & $\begin{array}{l}\text { SEN } \\
(\%)\end{array}$ & & & & \\
\hline $\begin{array}{l}\text { Perrot } \\
\text { et al. } \\
{[16] \text {, }} \\
2014\end{array}$ & 23 & $\begin{array}{l}8 \\
\text { regions }\end{array}$ & $\begin{array}{l}{ }^{18} \mathrm{~F}- \\
\text { Fluorocholine }\end{array}$ & 60 & 86 & 86 & 79 & 70 \\
\hline $\begin{array}{l}\text { Eiber et } \\
\text { al. [5], } \\
2016\end{array}$ & 53 & $\begin{array}{l}6 \\
\text { regions }\end{array}$ & $\begin{array}{l}{ }^{68} \mathrm{Ga}- \\
\text { PSMA }\end{array}$ & 58 & 82 & 82 & 76 & 97 \\
\hline $\begin{array}{l}\text { Lee et } \\
\text { al. [17], } \\
2016\end{array}$ & 31 & $\begin{array}{l}6 \\
\text { regions }\end{array}$ & $\begin{array}{l}{ }^{18} \mathrm{~F}- \\
\text { Choline }\end{array}$ & 58 & 58 & 87 & 73 & 82 \\
\hline & & & $\begin{array}{l}{ }^{18} \mathrm{~F}- \\
\mathrm{FDG}\end{array}$ & & & & 64 & 80 \\
\hline $\begin{array}{l}\text { Hicks et } \\
\text { al. [18], } \\
2018\end{array}$ & 32 & $\begin{array}{l}30 \\
\text { regions }\end{array}$ & $\begin{array}{l}{ }^{68} \mathrm{Ga}- \\
\text { PSMA }\end{array}$ & $67^{*}$ & $71^{*}$ & $71^{*}$ & $42^{*}$ & $79^{*}$ \\
\hline $\begin{array}{l}\text { Jambor } \\
\text { et al. } \\
{[19]} \\
2018\end{array}$ & 26 & $\begin{array}{l}12 \\
\text { regions }\end{array}$ & $\begin{array}{l}{ }^{18} \mathrm{~F}- \\
\mathrm{FACBC}\end{array}$ & $\begin{array}{l}74^{* *} \\
77\end{array}$ & $\begin{array}{l}88^{* *} \\
99\end{array}$ & $\begin{array}{l}88^{* *} \\
99\end{array}$ & $\begin{array}{l}50^{* *} \\
84\end{array}$ & $\begin{array}{l}90^{* *} \\
96\end{array}$ \\
\hline $\begin{array}{l}\text { Park et } \\
\text { al. [20], } \\
2018\end{array}$ & 33 & $\begin{array}{l}2 \\
\text { regions }\end{array}$ & $\begin{array}{l}{ }^{68} \mathrm{Ga}- \\
\text { PSMA }\end{array}$ & 53 & 100 & 100 & 86 & 88 \\
\hline
\end{tabular}




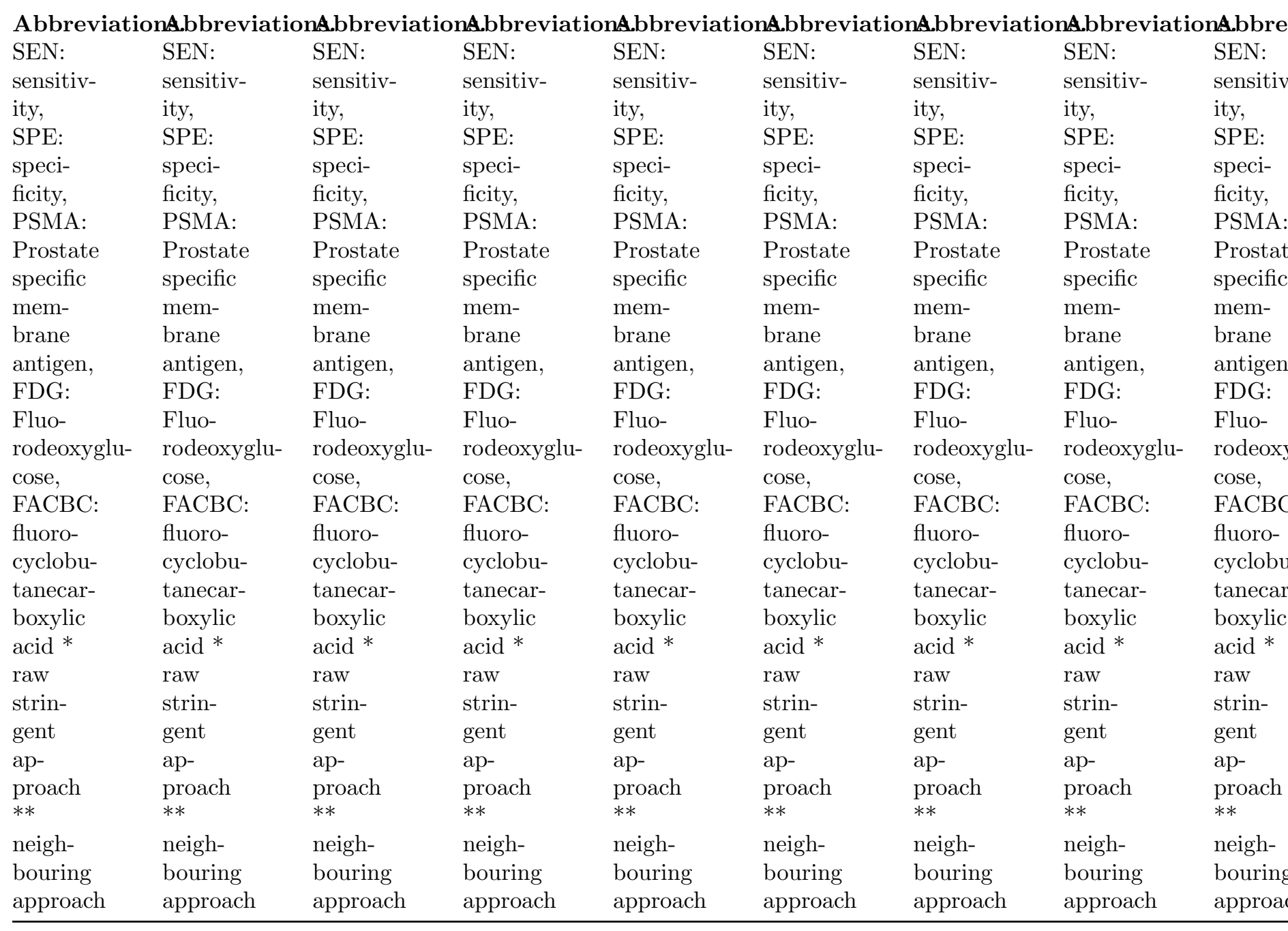

\section{FIGURE LEGENDS}

Fig. 1 A 62-year-old patient with an ISUP grade group 3 prostate cancer. a) Transverse T2-weighted image of mpMRI (lesion drawn by red line). b) Transverse dynamic contrast-enhanced image of mpMRI (lesion drawn by red line). c)Transverse diffusion-weighted image of mpMRI (lesion drawn by red line).d) Transverse sequence of ${ }^{68} \mathrm{Ga}$ PSMA PET / MRI (pathological uptake drawn by red line) e) Hematoxylin and eosin gross section histopathology shows a corresponding tumour focus.f) Tumour mapping created by the pathologist.

Fig. 2 Receiver-operating-characteristic analysis of multiparametric MRI, ${ }^{68} \mathrm{Ga}-\mathrm{PSMA}$ PET/MRI, and combined imaging for detection of prostate cancer index tumour (AUC [CI \%95] $=0.73[0.67-0.80] ; 0,77[0,71$ $0,84] ; 0.82[0.76-0.87]$, respectively) 

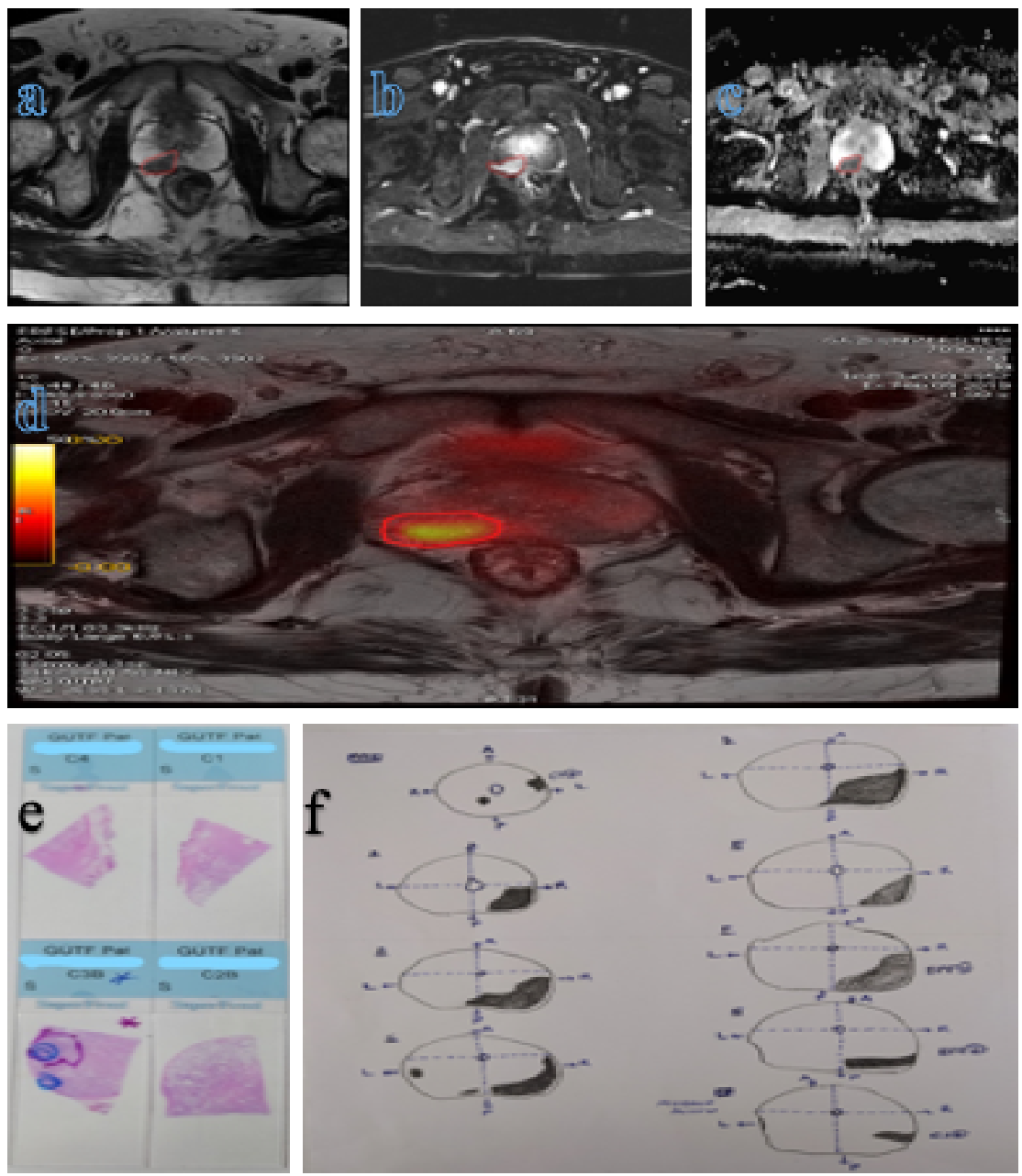


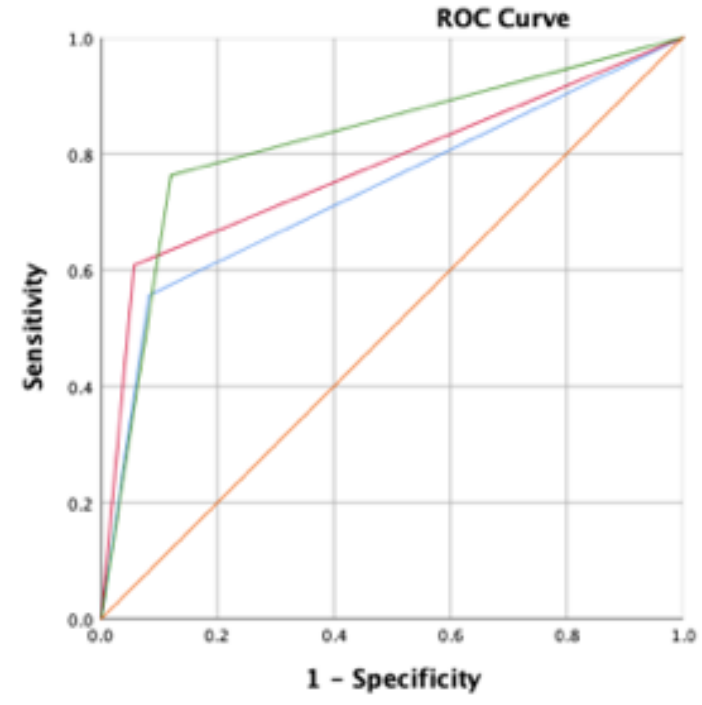

Source of the Curve

Multiparametric MRI

68(Ga) - PSMA PET/MR

- Combined Imaging

- Reference Line 